\title{
Retrospective Assessment of Donkeys' Health and Welfare problems in Dale Sadi District Haro Sabbu Veterinary Clinic, Oromia, Ethiopia
}

Firaol Bekele ( $\square$ tadessebekele7@gmail.com )

Haramaya University

Desita Goshu

Dale Sadi Livestock and Fishery development offfice, Oromia, Ethiopia

Darge Lulu

Dale Sadi Livestock and Fishery development offfice, Oromia, Ethiopia

Ebisa Wankila

Dale Sadi Livestock and Fishery development offfice, Oromia, Ethiopia

\section{Research Article}

Keywords: Donkey, Dale Sadi District, Pack Animal, Retrospective, Welfare problems, and Wound

Posted Date: June 30th, 2021

DOI: https://doi.org/10.21203/rs.3.rs-668832/v1

License: () (1) This work is licensed under a Creative Commons Attribution 4.0 International License. Read Full License 


\section{Abstract}

Background: Although donkey contributed vital role in human livelihoods through direct and indirect contributions to financial, human and social capital, emphasis has not been given to study the welfare issue which include health problems and management requirement. A retrospective study and questionnaire survey was conducted to assess the health and the welfare problem of donkeys coming to the Haro Sabbu Veterinary clinic for treatment at the Dale Sadi district, Haro SabbuVeterinary clinic, Oromia, Ethiopia. Data on 448 donkeys from 2018 to 2020 were analyzed from the data record sheet kept by the clinic.

Results: The most common case for wound occurrence were back sore 135(30.1\%), chest wound 37(8.3\%), bite 27(6.0\%) and combined wound of both back and bite $14(3.1 \%)$. The finding indicated that the occurrence of wound in donkeys having poor 170 (64.4\%), medium 41 (33.6\%) and good $7(11.6 \%)$ body condition and this was found to be statistically significantly associated $(\mathrm{p}=0.000)$. Among the common health problems and abnormalities encountered in donkeys back sore wound $135(30.1 \%)$, lameness $92(20.5 \%)$, parasitic infestation $60(13.6 \%)$, chest wound $37(8.3)$ and signs of colic $34(7.6 \%)$ were the major problems encountered in donkeys coming to clinic for treatment with there was no a statistically significant difference among different years. In addition to body condition, the occurrence of wounds was found to be statistically significantly associated with age category and work type. In addition, pack donkeys experienced higher lameness occurrences as compared to cart donkeys and it was statistically significant ( $P>0.05)$. In addition to health related problems, the questionnaire survey conducted also revealed welfare problems such as management condition, overloading, working hour, housing problems, and wounds due to harnessing were the major welfare problems of donkeys in the study area.

Conclusion: This retrospective study and questionnaire survey revealed the significant health and welfare problems of donkeys that need to be addressed in order to improve welfare status, their health and working efficiency. Therefore, there should be immediate awareness creation for community, government, community, local service providers and policy makers on welfare issue of donkey and health management in the study area in particular and in the country in general.

\section{Background}

It is has been long time since donkey being used by human being. They are a vital animal in supporting livelihoods of marginalized group in many region of Africa [1] Donkeys contribute vital role in human livelihoods through their direct and indirect contributions to financial, human and social capital. They are also important in communities' and households' socio-cultural lives, as they are often used in celebrations and in supporting households in need by being lent and shared between families [2].

Distribution of donkeys in the world shows $98 \%$ of them to be found in developing countries. Of this, Africa contributed more than 11.6 million for the world [1]. Ethiopia owned $40 \%$ of Africa donkey population with about 5.2 million donkeys which is $44 \%$ in Oromia, $34 \%$ in Amhara and $19 \%$ in Tigray regional states [3].

Donkey is still mentioned at the first as one of the most important drought animals contributing a significant role in the agriculture sector of developing country. In Ethiopia donkeys are considered as a better option than other draft animal because of their long time tolerance for dehydration, low sweating rate and good thermo-ability. Frequent occurrence of drought in Ethiopia causes an increase cattle death which may result in an increase donkey usage as a draft and pack animal largely in rural area and with a little in urban areas. Donkey contributed over $50 \%$ of animal energy scenario in the country. Donkey is well adapted more than both mule and horse in Ethiopian [4].

Although Donkey contributed prominent role in Ethiopia agriculture sector, much emphasis has not been given to study the welfare issue which include their physiology, nutritional requirement, health problems and management requirement. Donkey in Ethiopia at least in the donkey health and welfare project (DHWP) operation sites are subjected to variety of health disorder including multi parasite, back sore and other wounds, hoof problems, colic and various infectious diseases such as strangle, tetanus, Africa horse sickness (AHS) and others[5]. As the welfare of animals, donkey needs to be protected to live peacefully in their environment without affecting their health and welfare. They must not unnecessarily be neglected to have access for feed, water and shelter or abused by beating and harming and deprived of freedom of movement and exercise [6].

The objective of this retrospective study is thus, to document and compare the prevalence and distribution pattern of assessment of donkeys' health management and to identify common disease in donkeys in Dale Sadi District Haro Sabbu Veterinary Clinic, Oromia, Ethiopia. This work may benefit researchers, veterinary practitioners and other animal health workers.

\section{Results}

Number of recorded donkey cases handled and get treatment at Dale Sadi District, Haro Sabbu Veterinary clinics from 2018-2020

The data record format showed that some donkeys were coming to Dale Sadi district Haro Sabbu clinic to get treatments against different health problems during the year 2018-2020. A total of 448 donkey conditions and patient profile were recorded from casebook during the three year period at Haro Sabbu veterinary clinic (Figure 1).

Descriptive statistics of Donkey in the study sites with different variables from retrospective study 
The present study revealed that the body condition score of the donkeys is showed $58.9 \%$ of the donkeys were with poor body condition score, while it is only $13.8 \%$ of the donkeys had well to ideal body condition. The donkey in the study areas were predominantly $267(59.6 \%)$ carry pack while $142(31.7 \%)$ were pulling a cart (Table 1$)$.

Table 1: Descriptive statistics of Donkey in the study sites with different variables

\begin{tabular}{|c|c|c|c|}
\hline Variables & Category & Examined animals & Percent \\
\hline \multirow[t]{2}{*}{ Sex } & Female & 210 & 46.9 \\
\hline & Male & 238 & 53.1 \\
\hline \multirow[t]{3}{*}{ Age } & Adult & 253 & 56.5 \\
\hline & Old & 102 & 22.8 \\
\hline & Young & 93 & 20.8 \\
\hline \multirow[t]{3}{*}{ Work type } & Cart & 142 & 31.7 \\
\hline & Not started work & 39 & 8.7 \\
\hline & Pack & 267 & 59.6 \\
\hline \multirow[t]{3}{*}{ Body condition } & Good & 62 & 13.8 \\
\hline & Medium & 122 & 27.2 \\
\hline & Poor & 264 & 58.9 \\
\hline Total & & 448 & 100.0 \\
\hline
\end{tabular}

\section{Common diseases problems of working donkeys diagnosed and treated at Dale Sadi Veterinary clinic}

The present retrospective study has revealed donkeys were suffering from multiple health and welfare problems in the study area. Wound problem (Back sore, Bite), lameness, colic, ophthalmic problems, accidental injury, different infectious and parasitic diseases were the major problems encountered in donkeys during the year 2018-2020 (Table 1). The common health problems and abnormalities in donkeys were back sore wound 135(30.1\%), lameness $92(20.5 \%)$, parasitic infestation 60(13.6\%), chest wound 37(8.3) and signs of colic 34 (7.6\%) (Table2).

Table 2: Common health problems of working donkeys diagnosed and treated at Dale Sadi district Haro Sabbu veterinary clinic ( $\mathrm{n}=448$ ).

\begin{tabular}{|c|c|c|c|c|c|c|c|c|c|c|c|c|c|}
\hline \multirow[t]{2}{*}{ Year } & \multirow[t]{2}{*}{ Examined } & \multicolumn{11}{|c|}{ Case presentation to clinic } & \multirow{2}{*}{$\frac{x^{2}}{11}$} \\
\hline & & $\begin{array}{l}\text { Back } \\
\text { Sore }\end{array}$ & Bite & $\begin{array}{l}\text { Bite } \\
\text { and } \\
\text { Back } \\
\text { sore }\end{array}$ & $\begin{array}{l}\text { Chest } \\
\text { wound }\end{array}$ & Colic & Infectious & Injury & Lameness & Ophthalmic & Parasitic & Prolapse & \\
\hline 2018 & 138 & $35(25.4)$ & $9(6.5)$ & $4(2.9)$ & $12(8.7)$ & $13(9.4)$ & $9(6.5)$ & $1(0.7)$ & $34(24.6)$ & $2(1.4)$ & 16(11.6) & $3(2.2)$ & \\
\hline 2019 & 162 & $58(35.8)$ & $9(5.6)$ & $4(2.5)$ & $12(7.4)$ & $13(8.0)$ & $9(5.6)$ & $2(1.2)$ & $28(17.3)$ & $3(1.9)$ & $22(13.6)$ & $2(1.2)$ & \\
\hline 2020 & 148 & $42(28.4)$ & $9(6.1)$ & $6(4.1)$ & $13(8.8)$ & $8(5.4)$ & $11(7.4)$ & $(0.0)$ & $30(20.3)$ & $2(1.4)$ & $22(14.9)$ & $5(3.4)$ & \\
\hline Total & 448 & $135(30.1)$ & $27(6.0)$ & $14(3.1)$ & $37(8.3)$ & $34(7.6)$ & $29(6.5)$ & $3(0.7)$ & $92(20.5)$ & $(1.6)$ & $60(13.4)$ & $10(2.2)$ & \\
\hline
\end{tabular}

\section{Prevalence of wound}

The overall prevalence of wound was $48.7 \%$. Most common sites of wound occurrence in the donkeys were back sore $135(30.1 \%)$; chest wound $37(8.3 \%)$; bite $27(6.0 \%)$ and combined wound of back and bite 14(3.1\%) (Figure 2). 
There was a statistically significant difference in the prevalence of wound among different age groups $(\mathrm{P}=0.002)$. In addition, pack donkeys experienced higher wound occurrences as compared to cart donkeys and it was statistically significant ( $P>0.05$. The finding also indicated that 170 (64.4\%), $41(33.6 \%)$ and $7(11.6 \%)$ were having wound in poor, medium and good body condition scores respectively. The body conditions of working donkeys were found to be statistically significantly associated with the occurrence of wound (Table 3 ). This study showed that $56.5 \%$ of the donkeys in Dale Sadi district used for work were adults while about $20.8 \%$ of the donkeys were young.

Table 3: The association of risk factors with wound occurrence, from Dale Sadi 'district, Ethiopia.

\begin{tabular}{|c|c|c|c|c|c|c|}
\hline Variables & & Number of examined donkey & Positive & Percentage & $x^{2}$ & p.value \\
\hline \multirow[t]{2}{*}{ Sex } & Female & 210 & 101 & 48.01 & 0.051 & 0.822 \\
\hline & Male & 238 & 117 & 49.2 & & \\
\hline \multirow[t]{3}{*}{ Age } & Young & 93 & 44 & 47.3 & 12.485 & 0.002 \\
\hline & Adult & 253 & 109 & 43.1 & & \\
\hline & Old & 102 & 65 & 63.7 & & \\
\hline \multirow[t]{3}{*}{ Year } & 2018 & 138 & 62 & 44.9 & 1.738 & 0.419 \\
\hline & 2019 & 162 & 85 & 52.5 & & \\
\hline & 2020 & 148 & 71 & 48.0 & & \\
\hline \multirow[t]{3}{*}{ Work type } & Pack & 267 & 105 & 39.3 & 26.793 & 0.000 \\
\hline & Cart & 142 & 94 & 66.2 & & \\
\hline & Not started yet & 39 & 19 & 48.7 & & \\
\hline \multirow[t]{3}{*}{ Body condition } & Poor & 264 & 170 & 64.4 & 71.885 & 0.000 \\
\hline & Medium & 122 & 41 & 33.6 & & \\
\hline & Good & 62 & 7 & 11.3 & & \\
\hline
\end{tabular}

\section{Prevalence of lameness}

Among 448 donkey patients admitted to the clinic to get treatment, 92(20.5\%) were treated for different types of lameness. The prevalence of lameness in pack carrying donkeys was found to be $49((18.4 \%)$. The common type of lameness were hoof problems $65(14.5 \%)$, joint problems $14(3.1 \%)$ and long bones problem 13(2.9\%) (Table 4).

Table 4: The association of type of work with lameness occurrence at study area.

\begin{tabular}{|c|c|c|c|c|c|c|c|}
\hline \multirow[t]{2}{*}{ Work type } & \multirow[t]{2}{*}{ Number of treated } & \multirow[t]{2}{*}{ Total lameness } & \multicolumn{3}{|c|}{ Types of Lameness treated } & \multirow[t]{2}{*}{$x^{2}$} & \multirow[t]{2}{*}{ p.value } \\
\hline & & & Hoof & Joint & Long bone & & \\
\hline Cart puling & 142 & 16(11.3) & $11(7.7)$ & $2(1.4)$ & $3(2.1)$ & 14.044 & 0.029 \\
\hline Still didn't started work & 39 & $7(17.9)$ & $5(12.8)$ & $2(5.1)$ & $0(0.0)$ & & \\
\hline Pack carrying & 267 & $69(25.8)$ & $49(18.4)$ & 10(3.7) & 10(3.7) & & \\
\hline Total & 448 & $92(20.5)$ & $65(14.5)$ & $14(3.1)$ & $13(2.9)$ & & \\
\hline
\end{tabular}

Results of questionnaire survey 
Demographic characteristics of interviewers showed educational background of the donkey owners showed $54.4 \%$ were illiterate and only 29.8 and $8.8 \%$ attended elementary and secondary school level, respectively. Regarding with age category over $54 \%$ of the donkey owners were adults (Table5).

Table 5: Demographic characteristic of interviewers in the study area

\begin{tabular}{|c|c|c|c|}
\hline Variables & & Interviewed & Percent \\
\hline \multirow[t]{4}{*}{ Education } & Illiterate & 62 & 54.4 \\
\hline & Primary & 34 & 29.8 \\
\hline & Secondary & 10 & 8.8 \\
\hline & More than secondary & 8 & 7.0 \\
\hline \multirow[t]{3}{*}{ Age } & Young & 18 & 15.8 \\
\hline & Adult & 62 & 54.4 \\
\hline & Old & 34 & 29.8 \\
\hline \multirow[t]{2}{*}{ Sex } & Female & 31 & 27.2 \\
\hline & Male & 83 & 72.8 \\
\hline \multirow[t]{5}{*}{ Peasant Assotation } & Awetu Birbir & 19 & 16.7 \\
\hline & Arere Chole & 13 & 11.4 \\
\hline & Awetu Gandaso & 14 & 12.3 \\
\hline & Gonsi Dereba & 34 & 29.8 \\
\hline & Haro sabbu & 34 & 29.8 \\
\hline
\end{tabular}

Results of Management and working condition of donkeys

Majority of the respondent (82.5\%) reported that donkeys in the study areas depend on both cereals/grain and grass feeding since. Over $42.1 \%$ of the owners reported that they work with their donkey three times per week, while $20.2 \%$ work twice a week. As observed in this study, over $79.8 \%$ of the owners reported that donkeys are housed at night together with other animals in purposely built enclosures. Our findings have shown that among those who explained their practice on the castration of their donkey about $53.5 \%$ castrate their donkey at veterinary clinic while $31.6 \%$ of the owner's choices traditional methods of castration practice. But $14.9 \%$ respondents were reported that they do not practice castration of their donkeys because they think that castration decline working capacity and life span of their donkeys. Regarding the use of improved harness $65.8 \%$ donkey owners did not used improved harness and only $34.2 \%$ of the owners had been using improved harness (Table 6).

Table 6: Result of ownership, management and working condition of donkeys in the study area 


\begin{tabular}{|c|c|c|c|}
\hline Variables & Category & Frequency & Percent \\
\hline \multirow[t]{3}{*}{ Castration condition } & Castrating at clinic & 61 & 53.5 \\
\hline & Castrating at home & 36 & 31.6 \\
\hline & Not castrating donkey & 17 & 14.9 \\
\hline \multirow{3}{*}{$\begin{array}{l}\text { Ownership of the } \\
\text { donkeys }\end{array}$} & One animal & 60 & 52.6 \\
\hline & Two animals & 36 & 31.6 \\
\hline & Three animals & 18 & 15.8 \\
\hline \multirow[t]{2}{*}{ Working type of donkey } & Cart & 20 & 17.5 \\
\hline & Pack & 94 & 82.5 \\
\hline \multirow{5}{*}{$\begin{array}{l}\text { Working times per } \\
\text { Week }\end{array}$} & One & 15 & 13.2 \\
\hline & Two & 23 & 20.2 \\
\hline & Three & 48 & 42.1 \\
\hline & Four & 18 & 15.8 \\
\hline & Five & 10 & 8.8 \\
\hline \multirow[t]{2}{*}{ Feeding practices } & Both cereals/grain and grass & 94 & 82.5 \\
\hline & Straw and grass & 20 & 17.5 \\
\hline \multirow[t]{2}{*}{ Housing practices } & Housed with other animals & 91 & 79.8 \\
\hline & Housed with other animals & 23 & 20.2 \\
\hline \multirow[t]{2}{*}{ Use of improved harness } & Not using improved harness & 75 & 65.8 \\
\hline & Using improved harness & 39 & 34.2 \\
\hline
\end{tabular}

According the above figure (Figure 3) most of the donkeys spend day time working, and have a limited time roaming around and/or grazing, if available. On average (7.71), a donkey was working per day for 4 to $10 \mathrm{~h}$ interval.

As shown on the Figure 4, the present study revealed that the majority of the respondents reported that the average weight that their donkeys load was $88.08 \mathrm{~kg}(50-120 \mathrm{~kg})$ for pack carrying donkey and $259 \mathrm{~kg}(245-480 \mathrm{~kg})$ for cart pulling donkey. The majority of load carried at a time was above the capacity of the animal, taking the assumption that a donkey should carry one third on its pack or a triple of its body weight if pulling in cart (The Donkey Sanctuary Ethiopia, annual report, 2017).

\section{Discussion}

This study has indicated many health, management and welfare problems in the donkeys to coming clinics to get treatments in and around Dale Sadi district, Haro Sabbu town. Although the majority of the donkeys $253(56.5 \%)$ were adults, about $102(22.8) \%$ of donkeys were old and $93(20.8 \%)$ young. With regard to this there are owners begin to use donkeys for work before their age are mature enough in this study area. Until donkeys age are mature enough, it is not recommended to use for work as this can expose them to several health and structural abnormality such as sore back problem and lameness[10].

Although good body condition was observed in 62(13.8\%) of the donkey, the majority 264(58.9) of the donkeys were seen with poor body condition. Another study in Ethiopia also agree with the current finding that majority of the donkeys were found poor body condition [10]. This may indicate that poor body condition might be one of the main risk factors for the high incidence of back sore, due to less muscle coverage of emaciated animals. The main reason for poor body condition score of donkey are health related problem, improper management related activity and scarcity of feed.

According to the current study result the overall occurrence of wound was $48.7 \%$, which is lower than the previous report which were $58.0 \%[11]$, 77.5\%[12] and $79.4 \%$ [13] in Ethiopia. The present finding is also lower than (59\%) the report from outside of Ethiopia in Jordan [14]. The difference in occurrence of wound at different study area in donkeys might be due to the variation in working conditions, educational level of donkey owner's, age at which the donkey begin work, management condition and body condition of donkeys [15].

Most common sites of wound occurrence in the donkeys were back sore 135(30.1\%) and chest wound. These finding is almost the same with the result of similar works done in Ethiopia [10,16] and Mexico [17]. The occurrence of back sore wound in the donkeys might be caused by an integration of several causative factors related with management, category of harness material and not well appropriate harnessing and lack of padding on the back of the animals [15]. Hence, there was a statistically significant difference in the prevalence of wound among different age groups, body condition score and types of work. 
Relating the work type with occurrences of wound, higher incidence of wound was seen in poor body condition 264(58.9\%) donkey than good 62(13.8\%). This finding is probably due to the fact that, donkeys with a poor body condition index might have less natural padding coverage, which could be protecting them from friction, lesions and pressure during carrying pack or pulling cart. But, the report from another study in morocco is not in agreement the finding of the current study [18].

The other causes for occurrence of wounds of donkey at this study site are bites. Bites may result due to bitten by different types of animals such as hyena, dog and it may also occur from fighting between males donkey, as the of castrating donkey is not well practiced in the areas, and this may lead to aggressive behaviour to each other[19,5].

This study revealed abnormalities in movement of donkey admitted to the clinic to get treatment were treated for different types of lameness and this may suggest that donkeys were overloaded which leads to tendon or other structural damage. The finding of this retrospective study also reflects the common type of lameness were hoof problems 65(14.5\%) which was less than the previous study report (18.2\%) in Mekelle city [20] and (32.2\%) in Jordan [21]. The observed incidence of hoof problems may result from lack of proper hoof trimming, the lack of veterinary services, travelling of donkeys in inappropriate rough land surface in the study area and this might have predisposed them to hoof puncture with sharp objects such as nails and broken glasses. In study conducted at different time by several authors similar hoof problems were reported in different area of Ethiopia and somewhere outside of Ethiopia [22, 5, 23, 24]

On this study, there was a statistically significant difference in the prevalence of lameness among different work types. Concerning work type higher prevalence of lameness was observed in pack carrying donkey than cart donkeys. This may shows that the donkeys are not in suitable condition with their owners. This might be due to less understanding of the behaviour of the donkeys by the owners, poor understanding of the animal welfare issues and less appropriate working management functioning.

This study revealed colic cases $34(7.6 \%)$ as one of health problems encountered at the study area. Colic occurrence at this study area might be due to the ingestion of a foreign body such as plastic materials and impaction due to ingestion of excessive coarse, dry and high fiber feeds which may cause gastrointestinal disturbance. These findings are similar with the finding of other author in Ethiopia [5].

Among the finding of cases parasitic infestation, different types of infectious cases, rectal prolapse and ophthalmic problem in this study was consistent with the results of the study made by other author from Ethiopia $[5,25]$.

Results of questionnaire survey showed that majority of donkey owners were not having knowledge on donkey welfare issues. This may result from due to the educational level attained by majority of the donkey owner illiterate and also most of them are not practice improved harness which compromise welfare of donkeys.

According to this study the average weight that their donkeys load was $88.08 \mathrm{~kg}(50-120 \mathrm{~kg})$ for pack carrying donkey and $259 \mathrm{~kg}(245-480 \mathrm{~kg})$ for cart pulling donkey. Generally, a donkey should not carry more than one third of its body weight [15]. It is believed that the overloading and overworking are the predisposing factors for the occurrence of wound [26]. External injuries due to overwork and overload have also reported by other scholars [13, 18, and 27].

The finding of questionnaire survey also showed majority of the respondent (82.5\%) reported that donkeys in the study areas depend on only both cereals/grain and grass feeding which could be the main risk factor for poor body condition. This clearly shows that apart from health and management related problems, shortage of feed may be a major contributory factor for poor body condition of the donkeys. This study result is similar to the other report from Ethiopia [10] in which poor body condition might also be one of the contributory factors for the high incidence of back sore, due to less muscle cover.

\section{Conclusion}

In this retrospective study there are a significant health, management and welfare problems of working donkeys in the study area. This study has also attempted to cast light on the significant health problems of working donkeys that need to be addressed in order to improve their health and working efficiency. Therefore, there should be massive awareness creation on animal welfare and health management to the people working with donkeys and the 
general public. There must be also significant endeavour at multiple stages; community, local service providers and policy level to improve the neglected welfare statue of working donkeys in the area in particular and in the country in general.

\section{Materials And Methods}

Study area and period

The study was conducted from January 2018 to December 2020 retrospectively by using donkeys' patient case registration books in Dale Sadi District Haro Sabbu Veterinary clinic, Oromia Western, Ethiopia. The Dale Sadi district is located in Ethiopia, Kellem Wollega zone of Oromia regional state, situated at 562 Kilometres West of Addis Ababa. The mean annual rain fall in Dale sadi district ranges from $1150-1300 \mathrm{~mm}$. The annual temperature ranges from $26-34{ }^{\circ} \mathrm{C}$. The district has altitudes ranging from 1200-2000 m above sea level. The district has large rivers like Birbir, Mardafo and Kile River. The areas have got a number of wild animals such as African buffaloes, Bush pigs, warthog, bush buck, kudu, hippopotamus, crocodiles, hyena, antelopes and snakes. Agriculture is the main stay of the livelihood of the society with mixed farming system and livestock play an integral role for agriculture [7]. The animal population of the district is estimated to be 85,189 cattle, 28,600 sheep, 19,699 goats, 181 horses, 470 mules, and 3839 donkeys [8].

\section{Study animals}

The study animals were Donkeys in Dale Sadi District of Haro Sabbu town and the surrounding local peasant association of Gonsi Dereba, Awetu Gandaso, Awetu Birbir and Arere Colle coming to Haro Sabbu Veterinary clinic for treatment against different health problems. Most of the donkeys were from the Gonsi Dereba and some are from the different surroundings Peasant Association (PA). The body condition score were classified as poor, medium and good by observing the body condition of the animals in the field [9]. The study animals were 448 donkeys' population and they were coming to the clinic for treatment from 5 kebeles' (the smallest administrative unit) of Dale district.

\section{Study design}

\section{Retrospective studies}

The case files of donkey from the clinical case record book of the Dale Sadi District, Haro Sabbu Veterinary clinic and personal case record book were used to retrospectively assess data on the different health, management and welfare problems of working donkeys from January 2018 to December 2020 . The data collected retrospectively from the clinic for treatment were stored either electronically or on a data record sheet as a hard copy. Data from daily clinical record formats/sheet were entered into Microsoft Excel spread sheet. The data were coded into categories of clinical findings for each donkey. The categories were defined according to the systems affected, types of the problem and the cause of the problems. A total of 448 records of donkeys from 2018 to 2020 were extracted and organized for further analysis. The sampling unit was donkey patient encounters at Dale Sadi District Haro Sabbu Veterinary clinic to treat different acute and/or chronic illness.

Questionnaire survey

A structured questionnaire was designed and validated to study the welfare of donkeys including the number of donkeys owned, magnitude of work and management of donkeys. All individuals those are owners of donkey those have willingness to participate in the study and ready to give the required information were communicated to provide us with relevant information. The questionnaire was randomly administered to donkey owners, drivers coming to the Harro Sabbu veterinary clinic to collect relevant information about working donkey's welfare issues in the study area. For the purpose, total of 114 donkey owners were interviewed. The question was constructed in English, but during the interviews, the interviewer's were translating the questions were into Afan Oromo language. The questionnaire was administered through face to face interview.

\section{Data Collection}

An excel sheet data collection format was designed and then data was collected on the different health, management and welfare problems of working donkeys from January 2018 to December 2020 retrospectively by using patient case registration books in Dale Sadi District Haro Sabbu Veterinary clinic. For 
this study, 448 donkeys data record that contain the animal's characteristics (age, sex, breed, body condition, clinical signs and symptoms observed); disease diagnosis (name, empiric or physical clinical examination and confirmatory laboratory tests used) and prescriber's signature, level of education and years of experiences were collected retrospectively for 3 years period from January 01, 2018 to December 31, 2020. Cases of cattle, shoats, horses, mules and pet animals were not included in this study as they were programmed for another study in the future. Donkeys presented for castration were also not also included in this study.

\section{Data analysis}

The data collected was stored in the Microsoft-Excel Spread Sheet and analyzed using SPSS Version 20. Descriptive statistics was used to summarize the data. Pearson's Chi-square test was used to check the association between variables. P-value less than 0.05 at $95 \%$ confidence level was considered in interpreting the results.

\section{Declarations}

\section{Acknowledgements}

The authors would like to appreciate the staff members of the Dale Sadi district livestock and Fishery office and Haro sabbu Veterinary clinic for their assistance, willingness and cooperation during the period of this retrospective data collection.

\section{Authors' contributions}

All authors made significant contribution to title selection and designing of the study, retrospective data acquisition, questionnaire data collection, analysis and interpretation of data; took part in writing the article and revising it critically for important content; agreed to submit the manuscript; gave approval to be published; and agreed to be accountable for all aspects of this work.

\section{Funding}

Not applicable

\section{Availability of data and materials}

All data generated and analyzed during this study are included in Figure 1, Figure 2, Figure 3, Figure 4, Table 1, and Table 2. Table 3, Table 4 Table 5 and Table 6. However the raw data is available from the corresponding author up on reasonable request.

\section{Ethical approval and consent to participate}

Ethical approval is not applicable as the study was an observational study and no animal and human were subjected to suffer as a result of this study. But the researchers got permission for access to data from Dale Sadi district livestock and Fishery office. Confidentiality of treatment prescriber data for patients' was maintained by using unique code. All individuals involved in questionnaire are those who have willingness to participate in the interview and ready to give the required information were communicated to provide us with relevant information. Volunteer participants, from whom their verbal consent was obtained, were interviewed. Following detailed discussion about the objectives of the study with each participant, the face-to face interview was conducted.

Competing interests

The authors have not declared any conflict of interests.

\section{Author detail}

${ }^{1 *}$ Haramaya University College of Veterinary Medicine, P.O.Box 138, Oromia, Ethiopia.

${ }^{2}$ Dale Sadi District, Livestock and Fishery office, Kellem Wollega Zone, Oromia, Ethiopia 


\section{Abbreviations}

DHWP; Donkey Health and Welfare Project; WVA; World Veterinary Association; AHS

African Horse Sickness

\section{References}

1. Pearson RA. 'Use and Management of Donkeys by Poor Societies in Peri-urban of Ethiopia' in D.G Smith,T., Agajie,andL.More (eds),Alleviating Poverty In Peri urban Ethiopia by Improving the Health, Welfare and Management of donkeys,CTVM, Edinburgh. 2000; 2-5.

2. Donkey Sanctuary. Care of your donkey through the winter; 2017 Available at: http://www.thedonkeysanctuary.org.uk. Accessed date, 06 Febru 2021.

3. Svendsen E. Parasites abroad. The professional handbook of the donkey, $4^{\text {th }}$ ed. Whittet Book limited, London. 2008; 166-182.

4. Fielding D. Donkey power in Africa Rural transport world. Annual. Review. 1987; 63:22-30.

5. Getachew M, Feseha G, Trawford A, Bojia E, Alemayehu F, Amare B. Some common clinical cases and intervention made at the donkey health and welfare project-Donkey sanctuary, Debre Zeit, Ethiopia. Proceddings of the 4th International Colloquium on working equines, 20-26th April, 2002. Hama, Syria. 2002; 96-109.

6. Tekelye B. Legislation required for protecting farm andcompanion animals in Ethiopia. In: Feseha GA, Aberra G, YilmaA,SisayK, Kassa B. Ethiopian animal welfare Nulesletter, Addis Ababa Ethiopia. 2004; 2:2-3.

7. Dale Sadi Agricultural Development office, Harosebu, Ethiopia. 2021

8. Dale said Livestock development and Fishery office, Harosebu, Ethiopia. 2021.

9. Burn CC, Dennison T L, Whay HR. Relationships between behaviour and health in working horses, donkeys, and mules in developing countries. App. Anim. Behav.Scien. 2010b; 126:109-118. https://doi.org/10.1016/j.applanim.2010.06.007

10. Pearson RA, Alemayehu M, Tesfaye A, Allan EF, Smith DG, Asfaw M. Use and management of donkeys in peri-urban areas of Ethiopia. Report of Phase One of the CTVM/EARO Collaborative Project (Ethiopia).2001.

11. Herago T, Megersa M, Niguse A, Fayera T. Assessment on Working Donkey Welfare Issue in Wolaita Soddo Zuria District, Southern Ethiopia. Global Veterinaria. 2015; 14(6):867-875. DOl:10.5829/idosi.gv.2015.14.06.95169.

12. Curran MM, Feseha G, Smith DG. The impact of access to animal health services on donkey health and livelihoods in Ethiopia. Trop. Anim. HIth. Prod. 2005; 37(1):47-65.DOI: https://doi.org/10.1007/s11250-0059008-z.

13. Biffa D, Woldemeskel M. Causes and factors associated with occurrence of external injuries in working equines in Ethiopia.Int.J.App.Resea.Vet.Medi. 2006; 4(1):1.

14. .Burn CC, Pritchard JC, Whay HR. Observer reliability for working equine welfare assessment: problems with high prevalence of certain results. Animal Welfare. 2009; 18(2):177-187.

15. Pearson RA, Simalenga TE, Krecek RC. Harnessing and hitching donkeys, mules and horses for work. Centre for Tropical Veterinary Medicine, University of Edinburgh.2003.

16. Demelash B, Moges W. Causes in draught and factors associated with occurrence of external injuries in working equines in Ethiopia. Intern.J. Appl. Res. Vet. Med.2006; 4(1):7.

17. Rodriguez-Maldonado G. The principle problems of working donkeys in Mexico. In: Fielding D and Pearson R A (eds), Donkeys Mules and Horses in Tropical Agricultural Development. Centre for Tropical Veterinary Medicine, University of Edinburgh, Edinburgh pp. 1990; 138-139.

18. Sells PD, Pinchbeck G, Mezzane H, lbourki J, Crane M. Pack wounds of donkeys and mules in the Northern High Atlas and lowlands of Morocco. Equi. Vet. J. 2010; 42(3):219-226.doi:10.2746/042516409X478532. PMID:20486978.

19. Feseha G. 1997. Diseases and health problems of donkeys abroad. In: Svendsen, E.D (ed). The professional Handbook of the donkey, 3rd edn. Whittet Books Ltd. London, UK. 1997; 207-226.

20. Kumar N, Fisseha KK, Shishay N, Hagos Y. Welfare assessment of working donkeys in Mekelle city, Ethiopia. Global Veterinaria.2014; 12(3):314319.DOl:10.5829/idosi.gv.2014.12.03.82120

21. Sameeh M, Dirar M, Zain H, Sarah F. Equine diseases and welfare in Jordan retrospective study (1261 cases). Jord J. Agri, Scien. $2014 ; 10$ (3): $21-24$.

22. Soliman IA. Clinical observations of hoof deformities in donkeys. Assiut Veterinary Medical Journal 1989; 21:163.

23. Yilma J, Fesseha G, Sevendsen ED, Mohammed A. Health problems of Working Donkeys in Debre Zeit and Menagesha Rgions of Ethiopia. In: finding D and pearson A (ed): Donkeys, mules and horses in tropical agricultural development proceedings of a cllaguium held 3-6 September 1990, scot land. Centre for Tropical Veterinary Medicine, University of Edinburgn.1991; pp. 151-155.

24. Morgan R. The epidemiology of lameness in working donkeys in Addis Ababa and the central Oromia region of Ethiopia: a comparative study of urban and rural donkey populations. Proceeding of the fifth international colloquium on working equines. 30th Oct-2 ${ }^{\text {nd }}$ Nov, 2006, Addis Ababa, Ethiopia pp. 99109.

25. Ayele G, Feseha G, Bojia E, Joe A. Prevalence of gastro intestinal parasites of donkeys in Dugda district, Ethiopia, Livestock Research for Rural Development. 2006; 18:2-6. 
26. Julia B. Assessment of donkeys' welfare in Addis Ababa and Ambo, Ethiopia.

Master thesis Animal Science. Faculty of Veterinary Medicine and Animal Science.

Swedish University of Agricultural Sciences.2016.

27. Pritchard J, Lindberg C, Main J, Whay R. 2005. Assessment of the welfare of

working horses, mules and donkeys, using health and behavior parameters. Prevention and Veterinary Medicine.2005; 69(4): 265-283.

\section{Figures}

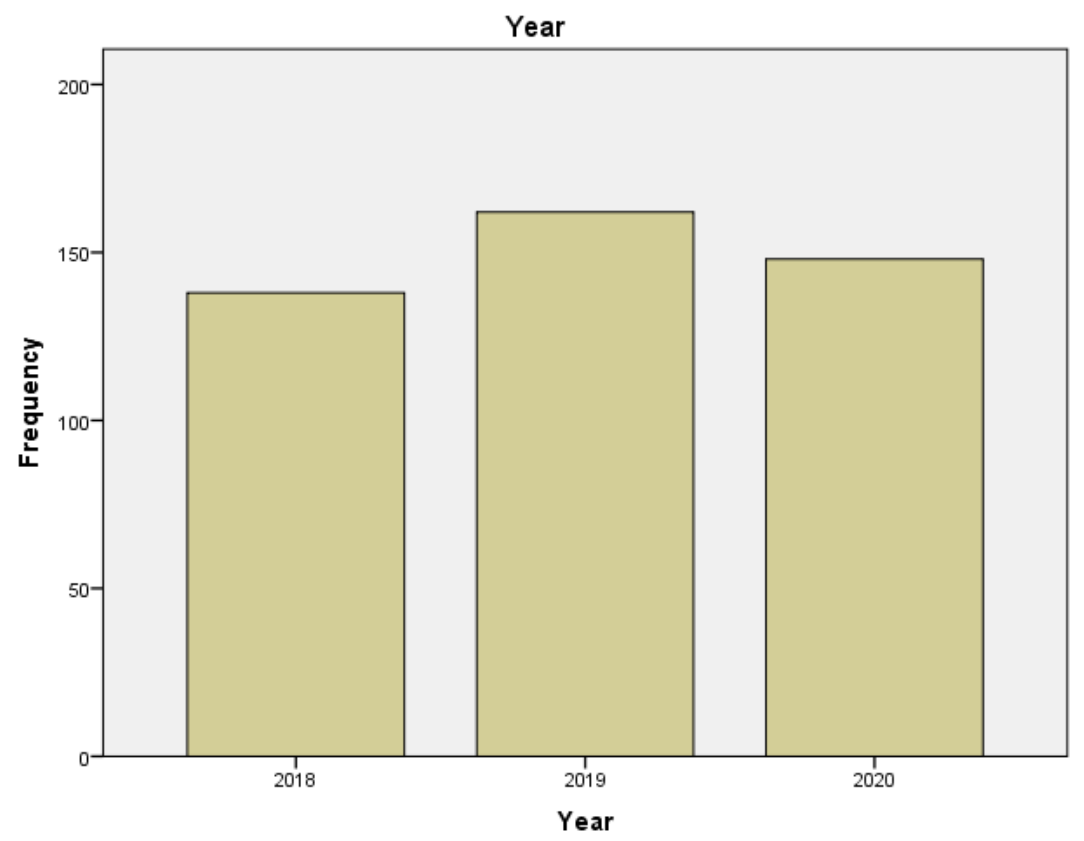

\section{Figure 1}

Number of donkeys got treatment at the Dale Sadi district clinic s during the year 2018-2020.

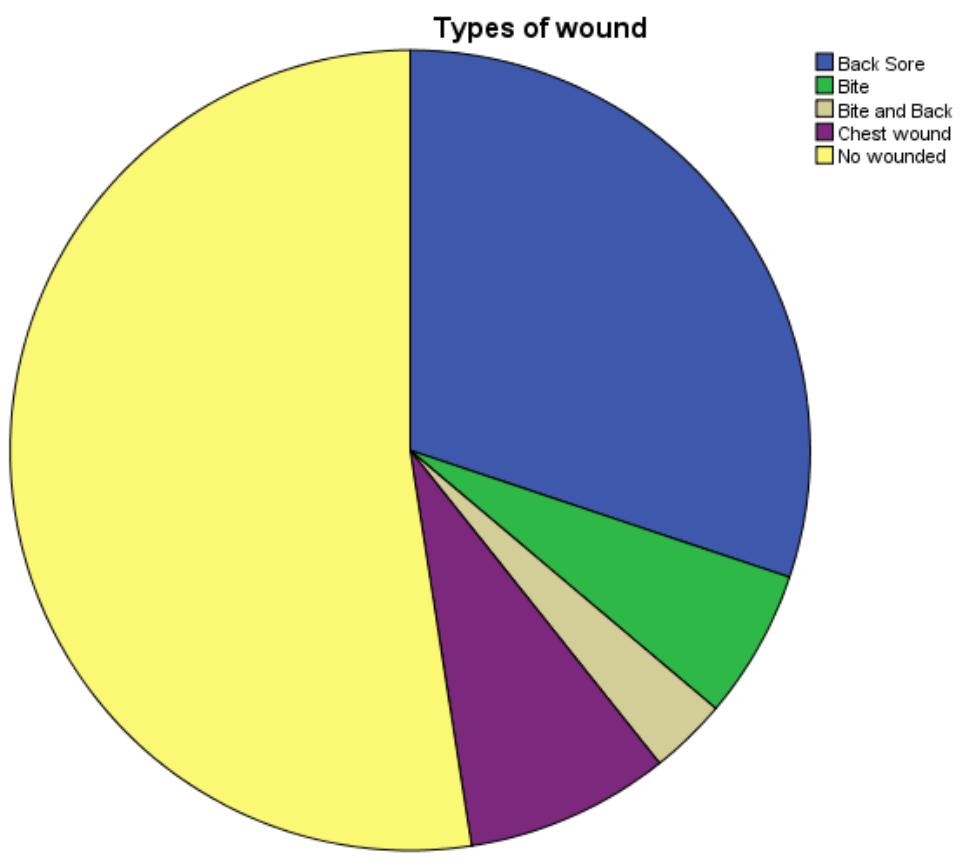

Figure 2

Types of wound problems of working donkeys treated at Dale Sadi Veterinary clinic during the years 2018-2020 $(n=448)$. 


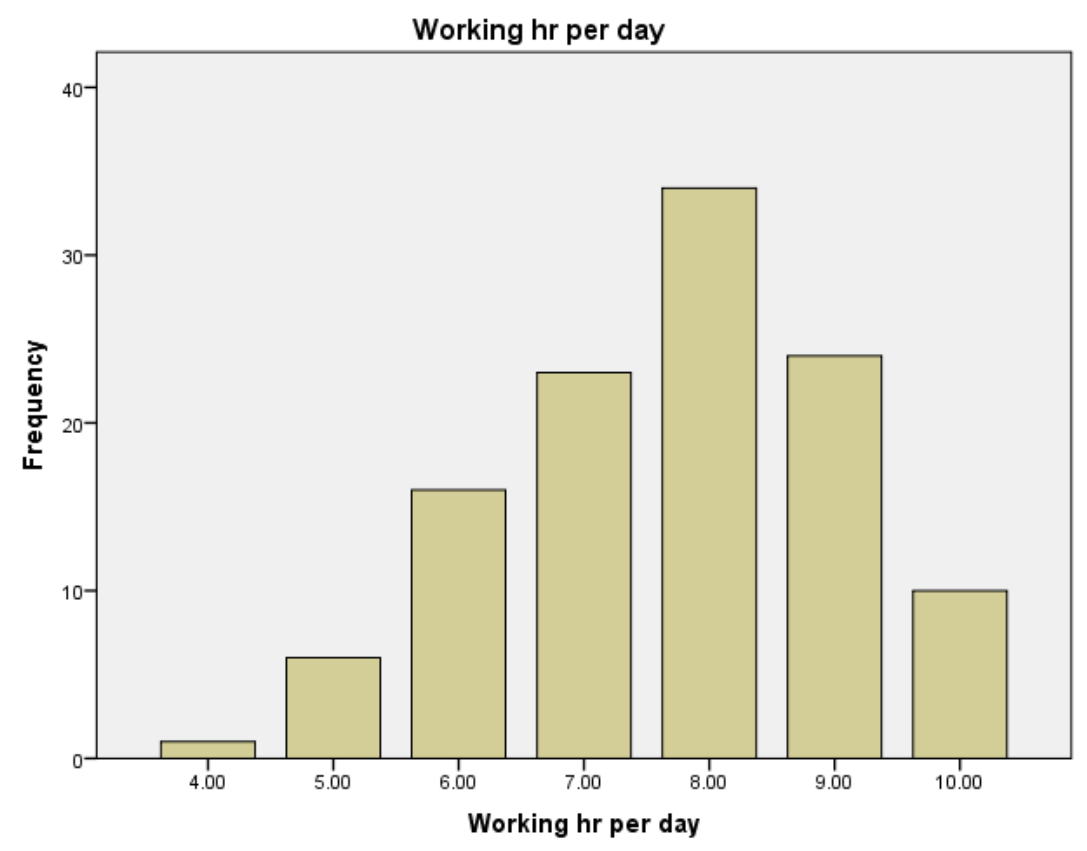

Figure 3

Frequency distribution of working hour per day of donkeys from interviewed respondent

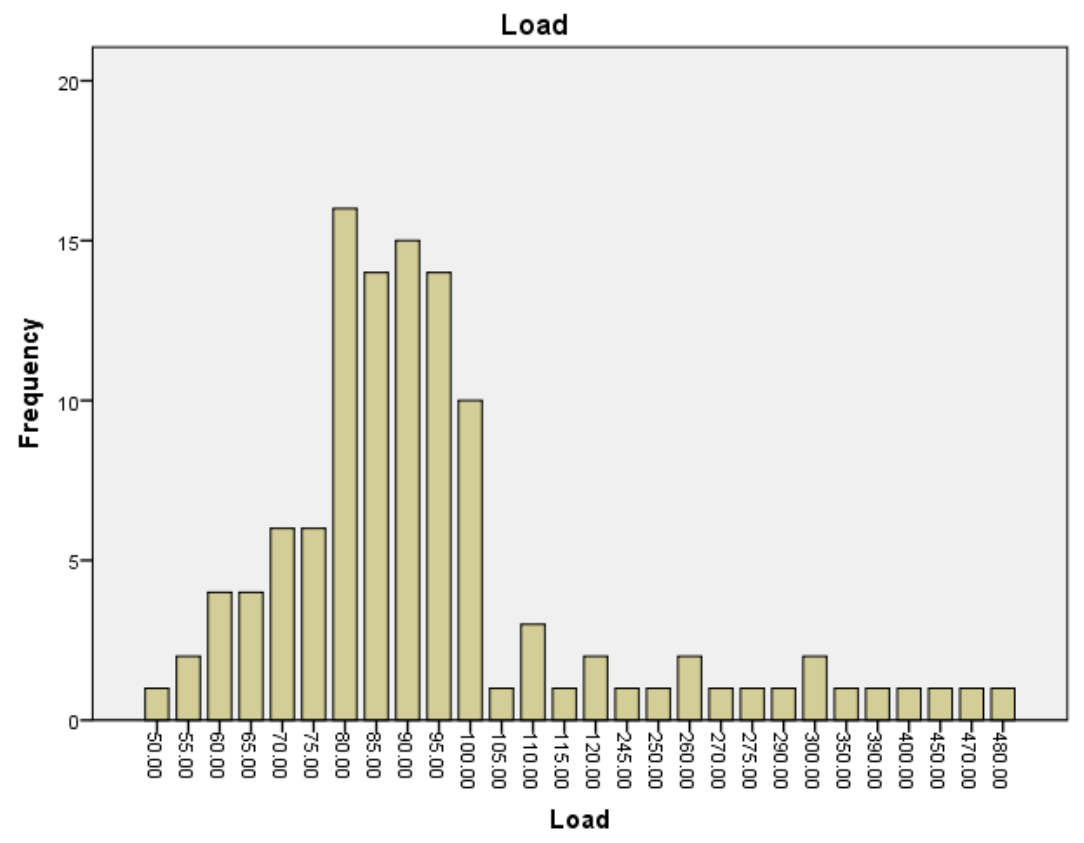

Figure 4

Frequency distribution of load per Kg of donkeys from interviewed respondent 